\title{
Leading in a Culture of Change
}

By Michael G. Fullan

Jossey-Bass, San Francisco, CA, 2001, 162 pp. plus index, \$25 hardcover

\section{Reviewed by Dr. Myron L. Pope}

Assistant Professor, Adult and Higher Education Program

University of Oklahoma

For administrators in higher education at all levels, and especially in student affairs, change is an ever-present concern and challenge. This change presents itself in many forms including funding concerns, shifts in student demographics, and frequent developments in technology. In order to survive in this culture of change, administrators must have the skills necessary to lead effectively. Michael Fullan's Leading in a Culture of Change attempts to provide a framework through which anyone, whether they are just beginning their role as a leader (as an orientation director) or if they are a seasoned leader, can follow and utilize to influence the change process.

Fullan, who is dean of the Ontario Institute for Studies in Education at the University of Toronto, provides a framework of five theoretical underpinnings that guide his support of the process necessary to counter the chaos that occurs during change. Based on his international status as an educational reformer and expert on organization change and leadership, Fullan articulated that if leaders pursue moral purpose, understand the change process, develop relationships, foster knowledge building, and strive for coherence, their overall effectiveness as a leader can be increased. He offered seven chapters in the book as the guidance to achieving this goal. Throughout these chapters, he included case studies from business and education that have utilized these theoretical concepts and succeeded in promoting leadership at all levels of the organization, and most importantly, successfully dealing with complex change.

Chapter 1-"A Remarkable Convergence," explained the purpose of this book, emphasizing that it is not a book on leaders who have the answers or who are charismatic. Thus, he does not focus on the characteristics of some known leader who has been successful in transforming some organization or who has provided the answer to complex problems encountered in these organizations. To the contrary, Fullan wanted the reader to understand that anyone can be a leader if they focus on mobilizing people as a group to solve problems. After he strongly stated that change cannot be managed or controlled, he introduced the five components of change and provided an introductory framework (to be elaborated on individually in subsequent chapter) of how these components of leadership are important in causing people to become committed to the cause. He emphasized at the end of the chapter that even though these components are important, leaders also must utilize energy, enthusiasm, and hopefulness to be effective 
in this culture of change.

Chapter 2: "Moral Purpose," addressed the notion that leaders must act with "the intention of making a positive difference in the lives of employees, customers, and society as a whole" (p. 3). Through two examples, one a education and the second a business, Fullan concluded that organizations that have promoted a strong sense of purpose and have adapted to their environments experienced longevity compared to those that neglected humanity and diversity and focused on economic prosperity. $\mathrm{He}$ further concluded that leaders in a culture of change must embrace the theory of sustainability, which constituted that environmental soundness, social justice, and economic viability exist in order for the company to succeed.

Chapter 3: "Understanding Change," explained the various types of change initially, but resolved that in order to understand the change process, the leader must realize that there are six elements of the process, including: (1) The goal is not to innovate the most; (2) It is not enough to have the best ideas; (3) Appreciate the implementation dip; (4) Redefine resistance; (5) Reculturing is the name of the game; and (6) Never a checklist, always complexity. Before elaborating on these, he discussed six leadership styles: coercive, authoritative, affiliative, democratic, pacesetting, and coaching. The pacesetting and coercive leadership styles were identified as counterproductive in terms of climate and performance. The latter part of the chapter provided details of understanding the change process by thoroughly entertaining the significance of each of the six elements of the process.

Chapter 4: "Relationships, Relationships, Relationships," assessed the necessity of relationships during leadership in a culture of change. Fullan asserted that effective leaders must be consummate relationship builders with groups both internal and external to the organization, especially those individuals different than themselves. He also noted that a critical aspect of being an effective leader is listening to and respecting the opinions of naysayers. He warned that not listening to these individuals will lead to eventual grief because of the lack of consensus building.

Chapter 5: "Knowledge Building," focused on the importance of leaders generating and promoting knowledge inside and outside of the organization. He argued that turning information into knowledge is a social process, and provided examples of how corporations and schools have attempted to translate "explicit knowledge (words and numbers that can be communicated in the form of data and information)" into "tacit knowledge (skills, beliefs, and understanding that are below the level of awareness)" (p. 80). He noted that it should not be a top-down process, but one in which everyone involved in the organization has an opportunity to share personal knowledge by allowing others to listen and react to their ideas.

Chapter 6: "Coherence Making," asserted that dynamic complex systems are chaotic. However, it is important for leaders to realize that this is a reality and recognize the value of this chaos. Consequently, as this is recognized, leaders must work to achieve coherence in the system. Fullan emphasized that leaders must realize that these systems will not operate in a linear manner and that they should not focus too much on maintaining coherence. Thus, it is important to create disturbances that promote the desired outcome or coherence. Organizations become more powerful and coherent by 
working through difficult problems.

Chapter 7: "The Hare and the Tortoise," emphasized the concepts of "slow knowing," "learning in context," and the need for leaders throughout the organization as important lessons for developing leaders in a culture of change. Slow knowing focused on the notion that effective leaders listen attentively and make decisions after thoroughly analyzing situations. They are aware also that if after initiating the five aforementioned leadership capacities and nothing happens, they should be patient. Additionally, learning in context is important in the leadership of organizations because it customizes the situation for those participating, and it involves the group in a social manner. Finally, Fullan emphasized that leadership should be encouraged at all levels within the organization. Thus, the organization does not depend on one "heroic leader" to solve its problems, but instead the entire organization of individuals should be committed to contributing to and leading the organization.

Fullan's focus on the individual promoting leadership throughout the organization as opposed to the individual reading the book and gaining a few select characteristics to personally become an effective leader is a different approach to leadership development. Other authors have tended to take the former approach to leadership development. However, as Fullan pointed out, this is counterproductive to his theory of the steps necessary to lead in a culture of change. His emphasis on moral purpose and relationship building are two areas that are important in consensus building, something that many leadership theories fail to take into consideration, and something key to those working in orientation programming. By gaining constituents' interest in a common cause and developing healthy relationships with them, individuals are more able to effectively lead in a culture of change. This book is an excellent asset to all in higher education who are new to leadership or are veterans in leading their organization in a culture of change. 